\title{
AKAP1 Protects from Cerebral Ischemic Stroke by Inhibiting Drp1-Dependent Mitochondrial Fission
}

\author{
DKyle H. Flippo, ${ }^{1 *}$ (D) Aswini Gnanasekaran, ${ }^{1 *}$ Guy A. Perkins, ${ }^{3}$ Ahmad Ajmal, ${ }^{2}$ Ronald A. Merrill, ${ }^{1}$ Audrey S. Dickey, ${ }^{5}$ \\ Susan S. Taylor, ${ }^{4}{ }^{\mathbb{C}}$ G. Stanley McKnight, ${ }^{6}$ Anil K. Chauhan, ${ }^{2}{ }^{\circ}$ Y uriy M. Usachev, ${ }^{1}$ and ${ }^{\circledR S t e f a n}$ Strack ${ }^{1}$ \\ ${ }^{1}$ Department of Pharmacology and Iowa Neuroscience Institute, ${ }^{2}$ Department of Internal Medicine, University of Iowa, Iowa City, Iowa 52242, ${ }^{3} \mathrm{National}$ \\ Center for Microscopy and Imaging Research, ${ }^{4}$ Department of Pharmacology, University of California, San Diego, California 92093, ${ }^{5}$ Department of \\ Neurology, Duke University, Durham, North Carolina 27708, and 'Department of Pharmacology, University of Washington, Seattle, Washington 98195
}

Mitochondrial fission and fusion impact numerous cellular functions and neurons are particularly sensitive to perturbations in mitochondrial dynamics. Here we describe that male mice lacking the mitochondrial A-kinase anchoring protein 1 (AKAP1) exhibit increased sensitivity in the transient middle cerebral artery occlusion model of focal ischemia. At the ultrastructural level, AKAP1 ${ }^{-1-}$ mice have smaller mitochondria and increased contacts between mitochondria and the endoplasmic reticulum in the brain. Mechanistically, deletion of AKAP1 dysregulates complex II of the electron transport chain, increases superoxide production, and impairs $\mathrm{Ca}^{2+}$ homeo- $^{-}$ stasis in neurons subjected to excitotoxic glutamate. $\mathrm{Ca}^{2+}$ deregulation in neurons lacking AKAP1 can be attributed to loss of inhibitory phosphorylation of the mitochondrial fission enzyme dynamin-related protein 1 (Drp1) at the protein kinase A (PKA) site Ser637. Our results indicate that inhibition of Drp1-dependent mitochondrial fission by the outer mitochondrial AKAP1/PKA complex protects neurons from ischemic stroke by maintaining respiratory chain activity, inhibiting superoxide production, and delaying $\mathrm{Ca}^{2+}$ deregu- $^{-}$ lation. They also provide the first genetic evidence that Drp1 inhibition may be of therapeutic relevance for the treatment of stroke and neurodegeneration.

Key words: ischemia; mitochondria; mitochondrial fission; neuroprotection; protein kinase; protein phosphorylation

\section{Significance statement}

Previous work suggests that activation of dynamin-related protein 1 (Drp1) and mitochondrial fission contribute to ischemic injury in the brain. However, the specificity and efficacy of the pharmacological Drp1 inhibitor mdivi-1 that was used has now been discredited by several high-profile studies. Our report is timely and highly impactful because it provides the first evidence that genetic disinhibition of Drp1 via knock-out of the mitochondrial protein kinase A (PKA) scaffold AKAP1 exacerbates stroke injury in mice. Mechanistically, we show that electron transport deficiency, increased superoxide production, and $\mathrm{Ca}^{2+}$ overload result from genetic disinhibition of Drp1. In summary, our work settles current controversies regarding the role of mitochondrial fission in neuronal injury, provides mechanisms, and suggests that fission inhibitors hold promise as future therapeutic agents.

\section{Introduction}

A-kinase anchoring proteins (AKAPs) are a group of proteins defined by their ability to bind regulatory subunits of protein

\footnotetext{
Received March 9, 2018; revised July 29, 2018; accepted Aug. 1, 2018.

Author contributions: K.H.F. wrote the first draft of the paper; G.A.P., R.A.M., A.K.C., Y.M.U., and S.S. edited the paper; A.S.D., S.S.T., A.K.C., Y.M.U., and S.S. designed research; K.H.F., A.G., G.A.P., A.A., R.A.M., A.S.D., and Y.M.U. performed research; S.S.T. and G.S.M. contributed unpublished reagents/analytic tools; K.H.F., A.G., G.A.P., A.A., R.A.M., Y.M.U., and S.S. analyzed data.

This work was supported by the Roy J. Carver Charitable Trust and lowa Neuroscience Institute (S.S., Y.M.U.), National Institutes of Health Grants NS056244, NS087908 to S.S., NS087068 and NS096246 to Y.M.U., DK54441 to S.S.T., GM32875 to G.S.M., and HL118246, HL118742,18EIA33900009 [American Heart Association (AHA)] to A.K.C.; an AHA postdoctoral fellowship (14P0ST20480080) to A.G.; and the Carver College of Medicine: Genomics Division, Viral Vector Core, and Central Microscopy Core.

The authors declare no competing financial interests.

*K.H.F. and A.G. contributed equally to this work.
}

kinase A (PKA) enabling targeting of the PKA holoenzyme to various subcellular compartments (Herberg et al., 2000; Carlson et al., 2003). The first AKAP to be identified, AKAP1 has an $\mathrm{N}$-terminal transmembrane domain and tethers PKA to the cytosolic surface of the outer mitochondrial membrane (OMM) to promote localized cAMP signaling (Affaitati et al., 2003; Ma and Taylor, 2008; Merrill and Strack, 2014; Jun et al., 2016). In addition to anchoring PKA, AKAP1 was shown to bind other signaling molecules, including Src kinase, protein phosphatase 1, calcineurin, and phosphodiesterase 4. A highly conserved

Correspondence should be addressed to either Dr. Stefan Strack or Yuriy M. Usachev, University of lowa College of Medicine, 51 Newton Road, lowa City, IA 52242, E-mail: stefan-strack@uiowa.edu or yuriy-usachev@uiowa.edu. DOI:10.1523/JNEUROSCI.0649-18.2018

Copyright $\odot 2018$ the authors $\quad 0270-6474 / 18 / 388233-10 \$ 15.00 / 0$ 
C-terminal $\mathrm{KH} /$ Tudor domain binds RNA and was suggested to facilitate cotranslational import of nucleus-encoded proteins into mitochondria (Merrill and Strack, 2014). Through its various associations, AKAP1 may orchestrate translational and posttranslational regulation of mitochondria-localized proteins. One of the critical targets of the AKAP1/PKA signaling complex is the mitochondrial fission enzyme Drp1 (dynamin-related protein 1; Dagda et al., 2011; Dickey and Strack, 2011; Kim et al., 2011; Merrill et al., 2011; Pryde et al., 2016).

Large GTPases of the dynamin family control mitochondrial shape and function. Aided by outer mitochondrial adaptor proteins, Drp1 translocates from the cytosol to the OMM for fission of the organelle. Fission is opposed by the outer mitochondrial fusion enzymes mitofusin 1 and 2 and the inner membrane fusion protein optic atrophy 1 (Opal; Otera et al., 2013). Precise regulation of mitochondrial fission/fusion is particularly important in neurons as mutations in these membrane-sculpting enzymes manifest with neurological symptoms in humans (Flippo and Strack, 2017a,b). Drp1 activity is regulated through a variety of posttranslational modifications including nitrosylation, SUMOylation, and phosphorylation (Chang and Blackstone, 2010). Perhaps best characterized, PKA-mediated phosphorylation of Drp1 at Serine 637 (S637 in human isoform 1 and S656 in rat isoform 1) inhibits its fission activity by as yet incompletely understood mechanisms (Chang and Blackstone, 2007; Cribbs and Strack, 2007), whereas dephosphorylation of the same residue by the $\mathrm{Ca}^{2+}$-dependent phosphatase calcineurin (PP2B) or PP2A activates the enzyme (Cribbs and Strack, 2007; Cereghetti et al., 2008; Merrill et al., 2013; Slupe et al., 2013).

Previous studies showed that AKAP1 protects cultured primary neurons against the mitochondrial toxin rotenone by inhibiting mitochondrial fission. Neuroprotection by AKAP1 required PKA anchoring and Drp1 phosphorylation at Ser637 (Dagda et al., 2011; Dickey and Strack, 2011; Merrill et al., 2011; Pryde et al., 2016). During in vitro ischemia/reperfusion injury or oxygen glucose deprivation, AKAP1 is degraded through ubiquitination via the E3 ligase Siah2, enhancing cell death in several culture models (Carlucci et al., 2008; Kim et al., 2011). According to transcriptomics studies, AKAP1 mRNA levels in the rodent hippocampus and cortex are unaltered $24 \mathrm{~h}$ after mid-cerebral artery occlusion (MCAO; Hori et al., 2012; C. Wang et al., 2017), indicating that injury regulates AKAP1 expression mainly through posttranscriptional mechanisms.

Here, we used AKAP $1^{-1-}$ mice to examine the contribution of AKAP1 to ischemic brain injury. AKAP $1^{-/-}$mice lack AKAP1 globally, causing female sterility (Newhall et al., 2006) and aggravating ischemic heart injury (Schiattarella et al., 2016). We found that AKAP1 loss worsens outcomes of transient MCAO, a model of focal ischemic stroke. Indicative of Drp1 hyperactivation, AKAP1 deletion diminished inhibitory phosphorylation of the fission enzyme at S637, enhanced its association with mitochondria, and decreased the size of mitochondria in the hippocampal CA1 region. Studies with lentivirus-transduced hippocampal cultures indicate that AKAP1 opposes excitotoxic injury by a mechanism that involves maintenance of inhibitory phosphorylation of Drp1 at S637. Drp1 inhibition contributes to neuronal survival by maintaining optimal function of the respiratory chain, and by curbing ROS production and $\mathrm{Ca}^{2+}$ deregulation during excitotoxic stress, all of which may contribute to protection from cerebral ischemia in vivo.

\section{Materials and Methods}

Animals. All animal work was performed in accordance with the guidelines of the animal ethics committee of the University of Iowa. Mice were group-housed in a colony maintained with a standard $12 \mathrm{~h}$ light/dark cycle and given food and water ad libitum. Experiments were performed with age-matched, and when possible litter-matched mice of both sexes except for MCAO and transmission electron microscopy (TEM) experiments, for which only male mice were used. Experiments were conducted according to the Guide for the Care and Use of Laboratory Animals, as adopted by the National Institutes of Health, and with approval of the University of Iowa, Institutional Animal Care and Use Committee.

To distinguish AKAP1 genotype by PCR, the following PCR primers were used: GGA GGC GAT CAC AGC AAC AAC CG (Rev), ATA CAG AAG CAG ATC ACT CAG GAG G (F-WT), CAG TCC CAA GGC TCA TTT CAG GCC (F-KO).

Middle cerebral artery occlusion. Focal cerebral ischemia-reperfusion injury was induced as described previously (Dhanesha et al., 2015). Briefly, mice were anesthetized with $1-1.5 \%$ isoflurane mixed with medical air and ischemia-reperfusion injury was induced by transiently occluding the right middle cerebral artery for $30 \mathrm{~min}$ with a 7.0 siliconized filament (Doccol) followed by $23 \mathrm{~h}$ of reperfusion. Body temperature was maintained at $37^{\circ} \mathrm{C} \pm 1.0$ using a heating pad. Laser Doppler flowmetry (Perimed Instruments) was used for each mouse, which showed that regional cerebral blood flow was reduced by $80-90 \%$ and recovered to $80-95 \%$ of baseline $(100 \%)$ after removal of the filament, suggesting adequate occlusion and reperfusion.

Mice were evaluated for motor-deficits $23 \mathrm{~h}$ post-reperfusion. The motor-deficit was scored on a four-point neurological scale as described previously (Dhanesha et al., 2015): 0, no observable neurological deficit (normal); 1, failure to extend left forepaw on lifting the whole body by tail (mild); 2, circling to the contralateral side but normal posture at rest (moderate); 3, leaning to the contralateral side at rest (severe); 4, no spontaneous motor activity. For infarct area determination, eight serial coronal sections were cut at $1 \mathrm{~mm}$ intervals from the frontal pole using a mouse Brain Matrix (Roboz Surgical Instrument). Serial sections were stained with $1 \%$ triphenyl-2, 3, 4-tetrazolium-chloride (TTC) for $15 \mathrm{~min}$ at $37^{\circ} \mathrm{C}$. Sections were scanned, digitalized and infarct areas were measured using ImageJ (NIH) software.

To correct for brain swelling due to edema after ischemia the corrected total infarct volume (\%) was calculated. Corrected infarct volume $(\%)=$ ([volume of contralateral hemisphere - (volume of ipsilateral hemisphere - volume of infarct)])/volume of contralateral hemisphere $X$ 100.

Transmission electron microscopy. Mice were transcardially perfused first with $37^{\circ} \mathrm{C}$ Ringer's solution to flush the blood and followed with $37^{\circ} \mathrm{C} 2.5 \%$ glutaraldehyde (electron microscopy grade) and $2 \%$ paraformaldehyde in $0.1 \mathrm{~m}$ sodium cacodylate buffer, $\mathrm{pH}$ 7.4. The brains were then dissected and placed in ice-cold fixative and immediately shipped to Guy Perkins at the Center for Research on Biological Systems, National Center for Microscopy and Imaging Research, University of California San Diego School of Medicine, La Jolla, CA. Samples were then processed, imaged, and analyzed as previously described (Perkins et al., 2001). Briefly, $80 \mu \mathrm{m}$ coronal sections of the hippocampus were cut in ice-cold fixative using a Leica VT1000S vibrating blade microtome. The brain slices were then washed with ice-cold 0.1 m sodium cacodylate $3 \times$ $10 \mathrm{~min}$ on ice followed by postfixation in $1 \%$ osmium tetroxide, $0.8 \%$ potassium ferrocyanide in $0.1 \mathrm{~m}$ sodium cacodylate for $3 \mathrm{~h}$ on ice. After three washes in ice-cold $\mathrm{ddH}_{2} \mathrm{O}$ for $10 \mathrm{~min}$ each, the tissue was stained in $2 \%$ uranyl acetate for $2 \mathrm{~h}$. Slices were dehydrated in an ethanol series of ice-cold 20,50, 70, and 90\%, and then three washes in $100 \%$ ethanol at RT for 10 min each. Samples were infiltrated in 67\% ethanol/33\% Durcupan ACM (Fluka; Sigma-Aldrich) for $3 \mathrm{~h}$ at RT with agitation, then $33 \%$ ethanol/67\% Durcupan ACM for $3 \mathrm{~h}$ at RT followed by 3 changes of $100 \%$ Durcupan for $8 \mathrm{~h}$ each at $22^{\circ} \mathrm{C}$ with agitation. The Durcupaninfiltrated slices were then flat-mounted between two mold-release glass slides and polymerized at $60^{\circ} \mathrm{C}$ for $2 \mathrm{~d}$. Semithick sections were cut using a Leica ultramicrotome and placed on 50-mesh uncoated copper clamshell grids. 
Colloidal gold particles $(15 \mathrm{~nm}$ ) were deposited on each side of the grid to serve as fiducial cues. The specimens were irradiated for $\sim 30 \mathrm{~min}$ before initiating a tilt series to limit anisotropic specimen thinning during image collection. During data collection, the illumination was held to near parallel beam conditions. Tilt series were captured using SerialEM (University of Colorado, Boulder, CO) software on a Tecnai Titan (FEI) TEM at $300 \mathrm{kV}$ Each double-tilt series consisted of first collecting 121 images taken at $1^{\circ}$ increments over a range of -60 to $+60^{\circ}$ followed by rotating the grid $90^{\circ}$ and collecting another 121 images. Tomographic reconstructions were generated using IMOD VR 4.3 software (University of Colorado).

The mitochondrial profile area was measured using the ImageJ area tool on EM images taken randomly all at the same magnification. To avoid bias, all the mitochondria in an image were measured. The percentage of mitochondria with ER strand contact was measured by counting the number of mitochondria with ER contacts divided by the total number of mitochondria in an image. An ER-mitochondria contact was defined as ER membrane touching the outer mitochondrial membrane or more commonly one or more filamentous tethers between ER and mitochondrial membranes.

Antibodies and reagents. The following commercially available antibodies were used: rabbit anti-phospho-Drp1Ser637 (Cell Signaling Technology), rabbit anti-phospho-Drp1 Ser616 (Cell Signaling Technology), rabbit anti-phospho-PKA-substrate (Cell Signaling Technology), rabbit anti-phospho-AKT-substrate (Cell Signaling Technology), mouse anti-Drp1 (BD Transduction Laboratories), mouse anti- $\beta$-tubulin (Developmental Studies Hybridoma Bank, University of Iowa), mouse anti-Opa1 (BD Transduction Laboratories), rabbit anti-Mfn2 (SigmaAldrich), mouse anti-Hsp60 (Proteintech), mouse anti-OXPHOS (Abcam), rabbit anti-VDAC (Abcam), rabbit anti-MnSOD (Rick Domann, University of Iowa), infrared fluorophore-coupled secondary antibodies (Licor), HRP-conjugated secondary antibodies (PerkinElmer). Dihydroethidium (DHE) was from Invitrogen. All other reagents were obtained from Sigma-Aldrich.

Subcellular fractionation. Before forebrain isolation mice anesthetized with ketamine/xylazine were perfused with an ice-cold PBS plus phosphatase inhibitor cocktail ( $0.1 \mathrm{~mm}$ ammonium molybdate, $2 \mathrm{~mm}$ EGTA, 2 mм EGTA, $50 \mathrm{~mm} \mathrm{NaF}, 2 \mathrm{~mm}$ sodium pervanadate (made fresh), $10 \mathrm{~mm}$ sodium pyrophosphate, $50 \mathrm{~nm}$ Calyculin A, $2 \mu \mathrm{M}$ FK506). Forebrain tissue was isolated and homogenized in isolation buffer [IB; $225 \mathrm{~mm}$ mannitol, 75 mм sucrose, 1 mм EGTA, 1 mм EDTA, 5 mм HEPES-KOH, $2 \mathrm{~mm}$ sodium pervanadate (made fresh), $10 \mathrm{~mm}$ sodium pyrophosphate, $20 \mathrm{~mm} \beta$-glycerophosphate, $1 \mathrm{~mm}$ benzamidine, leupeptin (1:2000), 100 nM microcystin-LR, $2 \mu \mathrm{M}$ FK506, PMSF (1:250), pH 7.2] using a power homogenizer. One hundred microliters of homogenate sample was taken and diluted in $4 \times$ sample buffer. An enriched mitochondrial fraction was then prepared similar to previously described (X. Wang et al., 2011).

Briefly, the remaining homogenate was then centrifuged at $1100 \times \mathrm{g}$ for $2 \mathrm{~min}$ at $4^{\circ} \mathrm{C}$ keeping the supernatant [post-nuclear supernatant (PNS)] and resuspending the pellet in $4 \times$ sample buffer (nuclear fraction). A $100 \mu \mathrm{l}$ sample of PNS was taken and diluted in $4 \times$ sample buffer. The remaining PNS was centrifuged at $17,000 \times g$ for $15 \mathrm{~min}$ at $4^{\circ} \mathrm{C}$. The supernatant from this step was further centrifuged at $80,000 \times g$ for 60 min to obtain a cytosolic fraction while the pellet was resuspended in IB and centrifuged over a $9 \% / 10 \%$ Percoll interface at $18,500 \times g$ for $15 \mathrm{~min}$ to obtain a mitochondrial enriched pellet. The mitochondrial enriched pellet was resuspended in IB and centrifuged at $10,000 \times g$ for $5 \mathrm{~min}$. The pellet was resuspended in $4 \times$ sample buffer as the enriched mitochondrial fraction.

Primary neuronal culture preparation. Primary hippocampal and cortical cultures were prepared from mouse neonates (P0 or P1). Brains were removed from pups and dissected, first removing dura and cortex, then the hippocampi. Tissues were stored in ice-cold Neurobasal Adult (NB-A; Invitrogen) media until processed. Tissues were incubated in HEPES buffered saline (HBS; $10 \mathrm{~mm}$ HEPES, $150 \mathrm{~mm} \mathrm{NaCl}$, pH 7.4, $\mathrm{Ca}^{2+} / \mathrm{Mg}^{2+}$-free), containing trypsin $(0.03 \%)$ at $37^{\circ} \mathrm{C}$ for $20 \mathrm{~min}$. Tissue was washed three times with $\mathrm{Ca}^{2+} / \mathrm{Mg}^{2+}$-free HBS before cells were dissociated by trituration. Cells were plated in NB-A complete (NB-A supplemented with B-27 $(1.5 \times)$, glutamine $(0.6 \mathrm{~mm})$, and gentamycin
$(1: 10,000))$ plus $5 \%$ horse serum on either poly-L-lysine or polyornithine and laminin-coated plates or glass coverslips, respectively. Media was changed $4 \mathrm{~h}$ following plating to NB-A complete lacking serum. Half of the media volume was replaced with fresh NB-A complete every $4 \mathrm{~d}$. Cultures were maintained at $37^{\circ} \mathrm{C}$ in a humidified environment of $95 \%$ air $/ 5 \% \mathrm{CO}_{2}$.

Glutamate toxicity in primary neuronal cultures. At $14 \mathrm{~d}$ in vitro (DIV), coverslips with cultured neurons were secured in a flow-through chamber fed $\mathrm{HH}$ buffer via a gravity perfusion system and mounted on an IX-71 epifluorescence microscope. For delayed calcium deregulation (DCD) and DHE experiments a baseline was established with a 2 min perfusion of $\mathrm{HH}$ buffer of the following composition (in mM): $140 \mathrm{NaCl}$, $5 \mathrm{KCl}, 1.3 \mathrm{CaCl}_{2}, 0.5 \mathrm{MgCl}_{2}, 0.4 \mathrm{MgSO}_{4}, 0.4 \mathrm{KH}_{2} \mathrm{PO}_{4}, 0.6 \mathrm{Na}_{2} \mathrm{HPO}_{4}, 3$ $\mathrm{NaHCO}_{3}, 10$ HEPES, 10 D-glucose, and at 310 mOsm, pH 7.4. The perfusion was then switched to a solution containing $100 \mu \mathrm{m}$ glutamate, 10 $\mu \mathrm{M}$ glycine, and $200 \mathrm{~nm}$ tetrodotoxin in $\mathrm{HH}$ (Castilho et al., 1999).

Fura-FF cytosolic calcium imaging. Cytosolic $\mathrm{Ca}^{2+}$ imaging was performed similarly to the protocol described in (Schnizler et al., 2008). Cortical or hippocampal cultures at 14 DIV were incubated at $22^{\circ} \mathrm{C}$ for 30 min in $2 \mu \mathrm{M}$ FuraFF/AM (Invitrogen) and $0.01 \%$ pluronic acid in $2 \mathrm{ml}$ $\mathrm{HH}$ buffer. The coverslip was then secured in a flow-through chamber fed HH buffer via a gravity perfusion system and mounted on an IX-71 epifluorescence microscope (Olympus). Fura-FF fluorescence was sequentially excited at 340 and $380 \mathrm{~nm}$ via a Polychrome V monochromator (TILL Photonics) with either a $20 \times$ lens (NA $=0.75$; Olympus) or a $40 \times$ oil-immersion objective lens ( $\mathrm{NA}=1.35$; Olympus). Fluorescent emission at 510 ( $80 \mathrm{~nm}$ bandwidth) $\mathrm{nm}$ was collected at $0.5 \mathrm{~Hz}$ sampling frequency by a Photonics IMAGO CCD camera coupled to TillVisION live acquisition software. $\left[\mathrm{Ca}^{2+}\right]_{\mathrm{i}}$ was quantified as background subtracted ratio $\mathrm{F} 340 / \mathrm{F} 380$.

Analysis of DCD latent period duration. For those neurons that produced DCD, latent period duration was measured as follows: the raw trace recording (converted to $\left[\mathrm{Ca}^{2+}\right]_{\mathrm{i}}$ as described above) was smoothed using a running average protocol (Sigma-Aldrich, Plot 13 software); the first derivative to the smoothed trace was then calculated and plotted as a function of time; the peak amplitudes corresponding to peak glutamate response slope and peak DCD slope were determined; the duration of time in minutes between the two peak slope amplitudes was calculated as the latent period duration.

DHE oxidation in primary neuronal cultures. At 14 DIV coverslips with cultured hippocampal or cortical neurons were secured in a flow-through chamber fed $\mathrm{HH}$ buffer via a gravity perfusion system and mounted on an IX-71 epifluorescence microscope (Olympus). DHE (5 $\mu \mathrm{M}$, Invitrogen) was perfused in with glutamate and DHE fluorescence was excited at $515 \mathrm{~nm}$ with emission collected at 595 (40 nm bandwidth) nm with a $20 \times(\mathrm{NA}=0.75$; Olympus $)$ or $40 \times$ oil-immersion lens $(\mathrm{NA}=1.35$; Olympus). Rate of DHE oxidation ( $\Delta$ fluorescence intensity/time) was calculated during constant perfusion of glutamate.

Respirometry. Oxygen consumption rate (OCR) was analyzed using a Seahorse Biosciences XF 96 Extracellular Flux analyzer (Agilent Technologies). Primary hippocampal or cortical cultures were plated on 96-well proprietary Seahorse Biosciences plates coated with poly-L-lysine. At 14 DIV NB-A media was replaced with unbuffered DMEM (DMEM base medium supplemented with $10 \mathrm{~mm}$ glucose, $1 \mathrm{~mm}$ sodium pyruvate, 2 mu L-glutamine, $\mathrm{pH} 7.4$ ) and incubated at $37^{\circ} \mathrm{C}$ for $1 \mathrm{~h}$ before respiration analysis. Four wells were recorded for each condition or genotype. For mitochondrial stress tests, inhibitors were injected in the following order; (1) basal, (2) oligomycin $(2 \mu \mathrm{M}),(3)$ FCCP $(2 \mu \mathrm{M})$, and (4) rotenone/ antimycin A $(10 \mu \mathrm{M})$. To measure complex II-dependent respiration, complex I was inhibited with $0.1 \mu \mathrm{M}$ rotenone, followed by addition of the complex II substrate rotenone $(12 \mathrm{~mm})$ as described previously (Giorgi-Coll et al., 2017). OCR was normalized to cell number following the assay using cresyl violet staining and measuring absorbance at $540 \mathrm{~nm}$ on a Biotek plate reader. Absorbance was converted to cell number using standards with known cell density (assessed after staining nuclei with Hoechst 33342).

Viral vectors. The Drp1-S637 phosphomimetic and de-phosphomimetic mutants (GFP-Drp1-S637D/A), AKAP1, and mitochondrial targeted GFP (MAS70-GFP) expression plasmids were described previ- 
A

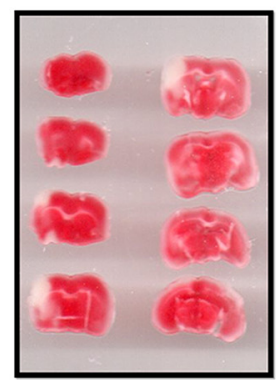

+/+

D
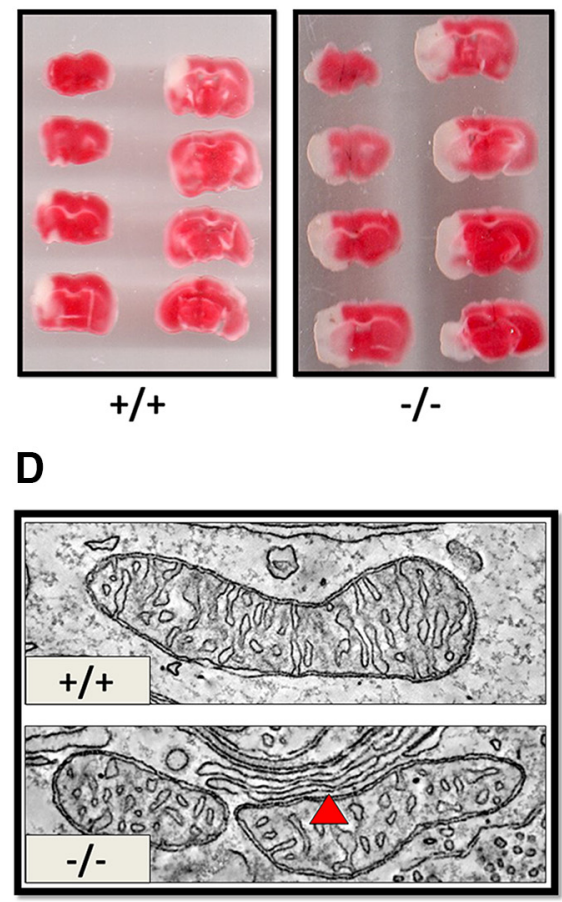

$-1$
B

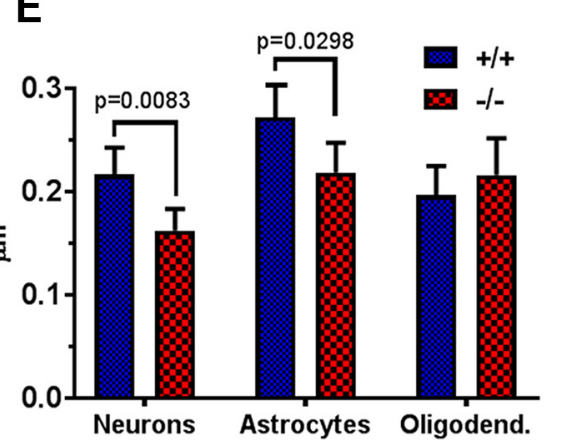

C

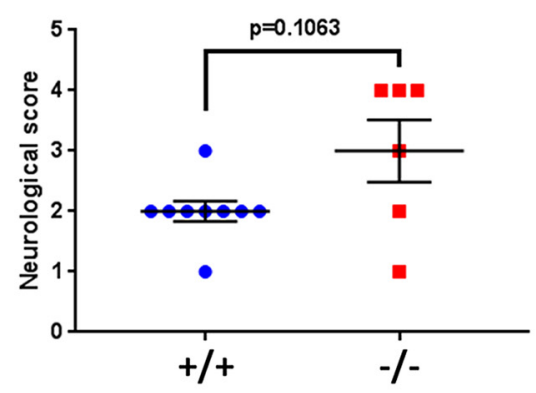

F

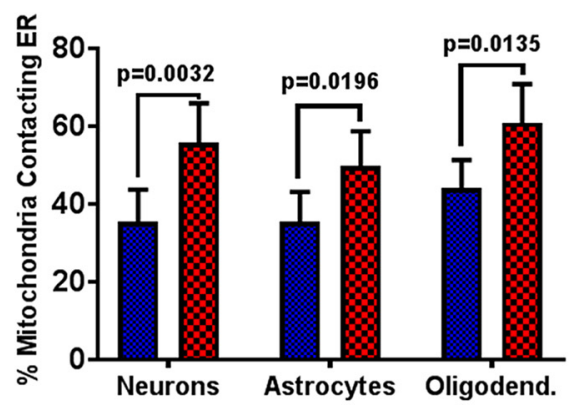

Figure 1. Deletion of AKAP1 increases infarct volume following transient MCAO and decreases mitochondrial profile area in the hippocampus. $A$, TTC staining of sectioned brains $24 \mathrm{~h}$ following 30 min MCA0 in AKAP1 ${ }^{+/+}$and ${ }^{-/-}$mice. The red region represents living tissue, whereas white demarcates the infarct area. $\boldsymbol{B}$, Percentage infarct volume and $(\boldsymbol{C})$ neurological score for $A K A P 1^{+/+}$and ${ }^{-/-}$mice. $D$, A representative slice through an ET volume of mitochondria in CA1 neurons of the hippocampus. The red arrow indicates contacts with the ER. E, Mitochondrial profile area in indicated cell types in the CA1 region of the hippocampus, and $(\boldsymbol{F})$ the percentage of mitochondria with close contacts with the ER. B, C, Data points represent mice $\left(n=13\right.$ for AKAP1 ${ }^{+/+}$ and $n=6$ for AKAP1 $^{-1-}$ ) and were analyzed by Mann-Whitney $U$ test. $E, n \geq 145$ mitochondria from neurons, $n=114$ mitochondria from astrocytes, and $n \geq 83$ mitochondria from oligodendrocytes from three mice/genotype were traced in $\geq 5-\mu \mathrm{m}$-spaced thin sections from the hippocampus. $F, n \geq 41$ neuronal, $n=44$ astrocytic, and $n \geq 42$ oligodendrocytic mitochondrial volumes were generated using ET from three mice/genotype. Data are presented as mean $\pm 95 \% \mathrm{Cl}$ and were analyzed by two-way ANOVA with Holm-Sidak's multiple-comparisons test. The abundance of several mitochondrial inner membrane and matrix proteins in total forebrain homogenates is unchanged in the AKAP1 ${ }^{-1-}$ (Figure 1-1, available at https://doi.org/10.1523/JNEUROSCI.0649-18.2018.f1-1).

ously (Cribbs and Strack, 2007; Cereghetti et al., 2008; Dagda et al., 2011; Dickey and Strack, 2011; Merrill et al., 2011). The Drp1 splice variant used includes exons 3,16, and 17 because these are preferentially included in neurons (Uo et al., 2009). Viruses were generated at the University of Iowa Viral Vector Core. Lentiviral expression under the CAG promoter in pFIV3.2-CAGmcs was used in all experiments described in this paper. A H1 promoter-shRNA cassette was inserted into the MfeI site of the viral vector to silence endogenous Drp1 (Cribbs and Strack, 2007). Primary hippocampal and cortical neurons were infected at 7 DIV by removing $1 / 2$ the media volume from each well and replacing with NB-A media containing virus $(1: 1000-1: 1500)$. After $6 \mathrm{~h}$ incubating at $37^{\circ} \mathrm{C}$ total media volume was removed and replaced with conditioned NB-A media.

Experimental design and statistical analysis. Number of animals, brain sections, cultures, and cells analyzed for each experiment in this study are specified in the figure legends and were justified using power analysis. Only male mice were used for Figure 1 and equal proportions of male and female mice were used for experiments in all subsequent figures. Unless otherwise indicated in the figure legends, data were analyzed by twotailed Student's $t$ tests with Welch correction for single comparisons and by one-way or two-way ANOVA for multiple comparisons with post hoc tests as indicated. Error bars are the $95 \%$ confidence interval (CI) unless stated otherwise. Data were analyzed and graphed using GraphPad Prism v7.0 for Windows.

\section{Results}

Mice lacking AKAP1 exhibit increased infarct following transient cerebral ischemia

AKAP1 has a protective function in several models of cell stress (Affaitati et al., 2003; Dagda et al., 2011; Kim et al., 2011; Merrill et al., 2011; Schiattarella et al., 2016), and hypoxia leads to proteasomal degradation of AKAP1 (Carlucci et al., 2008; Kim et al., 2011). In cultured primary hippocampal neurons overexpression of AKAP1 attenuates, while AKAP1 knockdown enhances rotenone-induced apoptosis (Merrill et al., 2011). In vivo, a recent report shows that deletion of AKAP1 in mice increases heart damage following permanent coronary artery ligation (Schiattarella et al., 2016). With these findings in mind we hypothesized that mice lacking AKAP1 would also exhibit greater susceptibility to cerebral ischemia. To model ischemic stroke, we transiently occluded the MCA of littermate mice derived from crosses of AKAP $1^{-1+}$ mice. As assessed by laser Doppler flowmetry, the degree of occlusion and subsequent reperfusion of the MCA territory was similar in wild-type and $\mathrm{AKAP} 1^{-/-}$mice (data not shown). However, cerebral infarct volume, as detected by a vital stain, was significantly increased in AKAP $1^{-1-}$ mice $24 \mathrm{~h}$ following $30 \mathrm{~min}$ of MCAO (Fig. $1 A, B$ ). The worsened stroke outcome of AKAP $1^{-1-}$ mice was evident behaviorally, as quantified as an increase in neurological scores (Fig. 1C).

Deletion of AKAP1 results in smaller mitochondria and more contacts with the endoplasmic reticulum

Loss of AKAP1 drives Drp1-dependent mitochondrial fission in neuronal cells (Dagda et al., 2011; Dickey and Strack, 2011; Kim et al., 2011; Merrill et al., 2011). Given that cerebral ischemia is associated with mitochondrial fragmentation and that pharmacological Drp1 inhibition was reported to provide ischemic pro- 



Figure 2. AKAP1 deletion increases Drp1 localization to mitochondria and decreases Drp1-S637 phosphorylation. $\boldsymbol{A}-\boldsymbol{D}$, Representative Western blot of total Drp1, Drp1-S637 phosphorylation (p), and Drp1-S616 phosphorylation in mitochondrial fractions from the forebrain of AKAP1 ${ }^{+/+}$and ${ }^{-1-}$ mice. Levels of total Drp1 and two mitochondrial fusion proteins (Opa1 and Mfn2) in total forebrain homogenates is unchanged by AKAP1 deletion (Figure 2-1, available at https://doi.org/10.1523/JNEUROSCI.0649-18.2018.f2-1). For quantification of total Drp1, blots were stained for total protein using Ponceau S and an area of each lane flanked by major bands and encompassing Drp1 was scanned for normalization. Data are presented as mean $\pm 95 \%$ Cl of $n=6$ mice $/$ genotype and were analyzed by Welch's $t$ test.

tection (Grohm et al., 2012; Zhang et al., 2013; Zhao et al., 2014; Li et al., 2015; Bordt et al., 2017), we evaluated mitochondrial ultrastructure using electron microscope tomography (Fig. 1D). Focusing on the CA1 region of the hippocampus, which is particularly susceptible to ischemic insults (Sugawara et al., 1999), we compared mitochondrial profile area in the soma of neurons, astrocytes, and oligodendrocytes between littermate AKAP1 ${ }^{+/+}$ and AKAP $1^{-1-}$ mice using conventional TEM. We observed a significant decrease in mitochondrial profile area in neurons and astrocytes of AKAP1 ${ }^{-1-}$ mice, but no size difference between genotypes was observed in oligodendrocytes (Fig. 1E).

The ER plays an important role in the initiation of mitochondrial fission, marking fission sites through preconstriction of the OMM (Friedman et al., 2011; Prudent and McBride, 2016). In addition, contacts between mitochondria and ER facilitate lipid and metabolite exchange and allow for communication between the two $\mathrm{Ca}^{2+}$ stores (Marchi et al., 2014; Vance, 2014). The number of mitochondrial profiles contacting ER membrane was significantly increased in the hippocampus of AKAP1 ${ }^{-1-}$ compared with wild-type mice (Fig. $1 F$ ). Interestingly, AKAP1 deletion increased contacts in neurons, astrocytes, and oligodendrocytes despite unaltered mitochondrial profile area in the latter, suggesting that the increase in the number of contacts with the ER is unrelated to enhanced mitochondrial fission.

Mitochondrial biogenesis involves division (fission) followed by growth of the newly divided mitochondria. The smaller size of mitochondria in AKAP $1^{-1-}$ mice could therefore be the conse- quence of a growth impairment, or perhaps precocious clearance of mitochondria by autophagy. To assess whether AKAP1 deletion affected mitochondrial mass, we examined proteins localized to different mitochondrial compartments by quantitative Western blotting of forebrain homogenates. No significant differences between genotypes were detected (Fig. 1-1, available at https://doi.org/10.1523/JNEUROSCI.0649-18.2018.f1-1), suggesting that AKAP1 primarily regulates the mitochondrial fission/fusion equilibrium, as opposed to mitochondrial biogenesis or mitophagy.

Mice lacking AKAP1 exhibit increased Drp1 localization to mitochondria and decreased Drp1-S637 phosphorylation AKAP1 can modulate Drp1 activity by recruiting PKA to the OMM to phosphorylate Drp1 at S637 (Dagda et al., 2011; Dickey and Strack, 2011; Merrill et al., 2011; Pryde et al., 2016). Conversely, dephosphorylation of Drp1 at S637 increases localization of Drp1 to the OMM to drive mitochondrial fission (Cribbs and Strack, 2007; Cereghetti et al., 2008; Merrill et al., 2013; Slupe et al., 2013). To examine Drp1 regulation by PKA/AKAP1 in vivo, we assessed Drp1 phosphorylation in mitochondrial fractions from the forebrain. AKAP $1^{-1-}$ significantly increased total Drp 1 levels in mitochondrial fractions (Fig. $2 A, B$ ). Additionally, Drp1 phosphorylation levels (phospho-S637/total Drp1) were significantly decreased in AKAP1 ${ }^{-1-}$ mice (Fig. $2 A, C$ ). This decrease was specific for the PKA site, because Drpl phosphorylation at S616, a site targeted by cyclin-dependent kinases and PKC (Ta- 
A
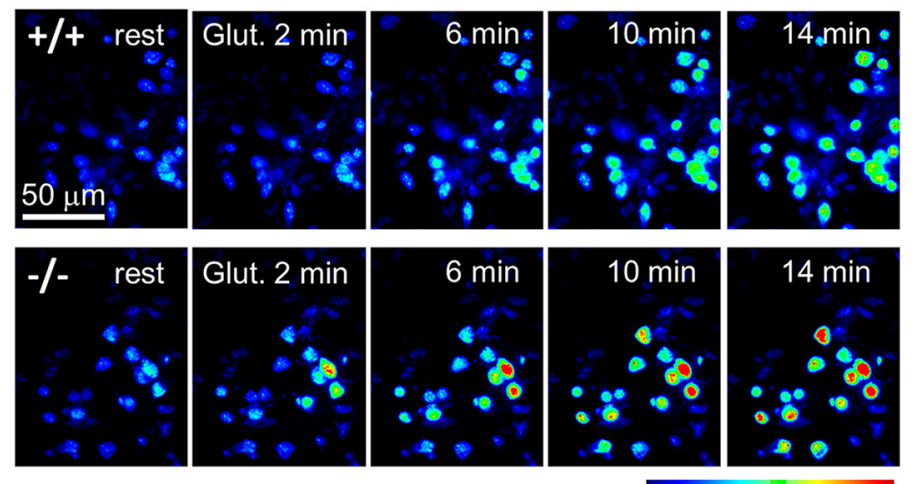

100

600

C

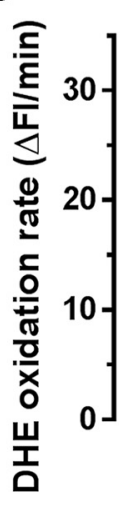

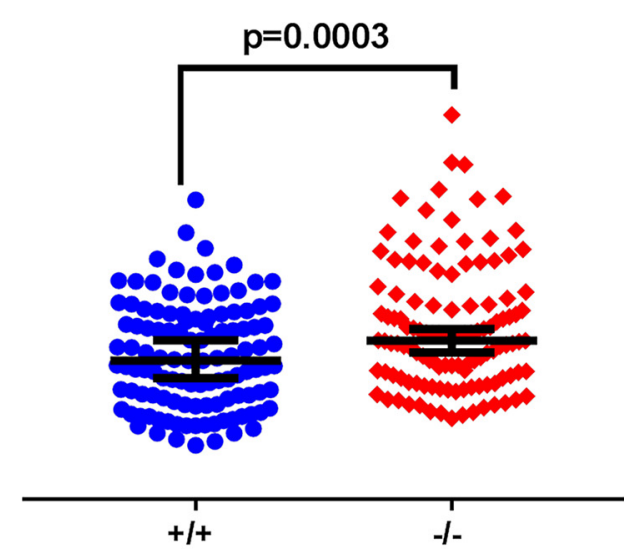

Hippocampal Neurons
B



Figure 3. AKAP1 deletion increases superoxide production in response to excitotoxic glutamate. $\boldsymbol{A}$, Representative images show color-coded fluorescence intensity of DHE in hippocampal neurons (14 DIV) at rest and at the indicated times after the start of $100 \mu \mathrm{m}$ glutamate superfusion. The color lookup table scale is shown at the bottom. $\boldsymbol{B}$, Fluorescence intensity traces of the superoxide indicator DHE in response to $100 \mu \mathrm{m}$ glutamate in AKAP1 ${ }^{+/+}$and ${ }^{-1-}$ hippocampal neurons. $\boldsymbol{C}, \boldsymbol{D}$, Summary plots of superoxide production rate after glutamate treatment in hippocampal $(\boldsymbol{C})$ and cortical $(\boldsymbol{D})$ neurons. Shown are median $\pm 95 \% \mathrm{Cl}$. Data points in $\boldsymbol{C}$ and $\boldsymbol{D}$ represent neurons $(n=61-118)$ from 3 to 4 mice/genotype and were analyzed by Welch's $t$ test.

guchi et al., 2007; Qi et al., 2011; Jahani-Asl et al., 2015), kinases not known to interact with AKAP1, was unaffected by AKAP1 deletion (Fig. 2A,D). Drp1 levels in total forebrain homogenates, as well as levels of the mitochondrial fusion proteins Mfn2 and Opal were also unaltered (Fig. 2-1, available at https://doi.org/ 10.1523/JNEUROSCI.0649-18.2018.f2-1) consistent with the notion that AKAP1 regulates mitochondrial dynamics by posttranslational modifications.

Deletion of AKAP1 increases superoxide production in response to excitotoxic glutamate

In the initial stages of cerebral ischemia, large amounts of glutamate released from neurons in the ischemic core trigger excitotoxic death in the surrounding penumbra (Ramos-Cabrer et al., 2011). Mitochondria-derived superoxide and other reactive oxygen species contribute to this secondary excitotoxic injury (Nicholls, 2004; Abramov et al., 2007). To determine whether AKAP1 influences superoxide production during excitotoxic insults, we cultured primary neurons from wild-type and $\mathrm{AKAP} 1^{-1-}$ neonate littermates (P0 or P1) and imaged superoxide production using the superoxide-specific fluorescent dye DHE after allowing cultures to mature for $14 \mathrm{~d}$. Cultures were prepared from both the cortex, which includes the MCA territory, and the hippocampus, which is part of the ischemic penum- bra after MCAO. Basal rates of DHE oxidation were unchanged (Fig. $3 A, B)$. However, application of glutamate $(100 \mu \mathrm{M})$ resulted in a significant increase in superoxide production rates in AKAP $1^{-1-}$ compared with wild-type neurons regardless of origin (hippocampus, Fig. $3 A-C$; cortex, $D$ ).

\section{AKAP1 deletion results in complex II dysfunction}

The mitochondrial respiratory (or electron transport) chain (ETC) is the main source of superoxide in ischemic and excitotoxic injury, and mutations in subunits or assembly factors of the ETC can cause neurodegenerative disorders (Koopman et al., 2013). To investigate potential OXPHOS abnormalities, mitochondrial fractions from forebrain were probed with an antibody mixture that detects one subunit of each of the five complexes (CI-CV). We detected increased expression of a complex II subunit in AKAP1 ${ }^{-1-}$ mice, whereas levels of subunits of other OXPHOS complexes were similar between genotypes (Fig. 4A, B). To address the functional implications of this apparent OXPHOS subunit imbalance, we evaluated OCR in neuronal cultures using the Seahorse extracellular flux analyzer. In the presence of $10 \mathrm{mM}$ glucose as a carbon source, we observed no difference in OCR (basal, leak, maximal, or non-mitochondrial; Fig. 4A) or extracellular acidification rate (data not shown) between AKAP1 ${ }^{-1-}$ and wild-type neurons, regardless of whether they were cultured 

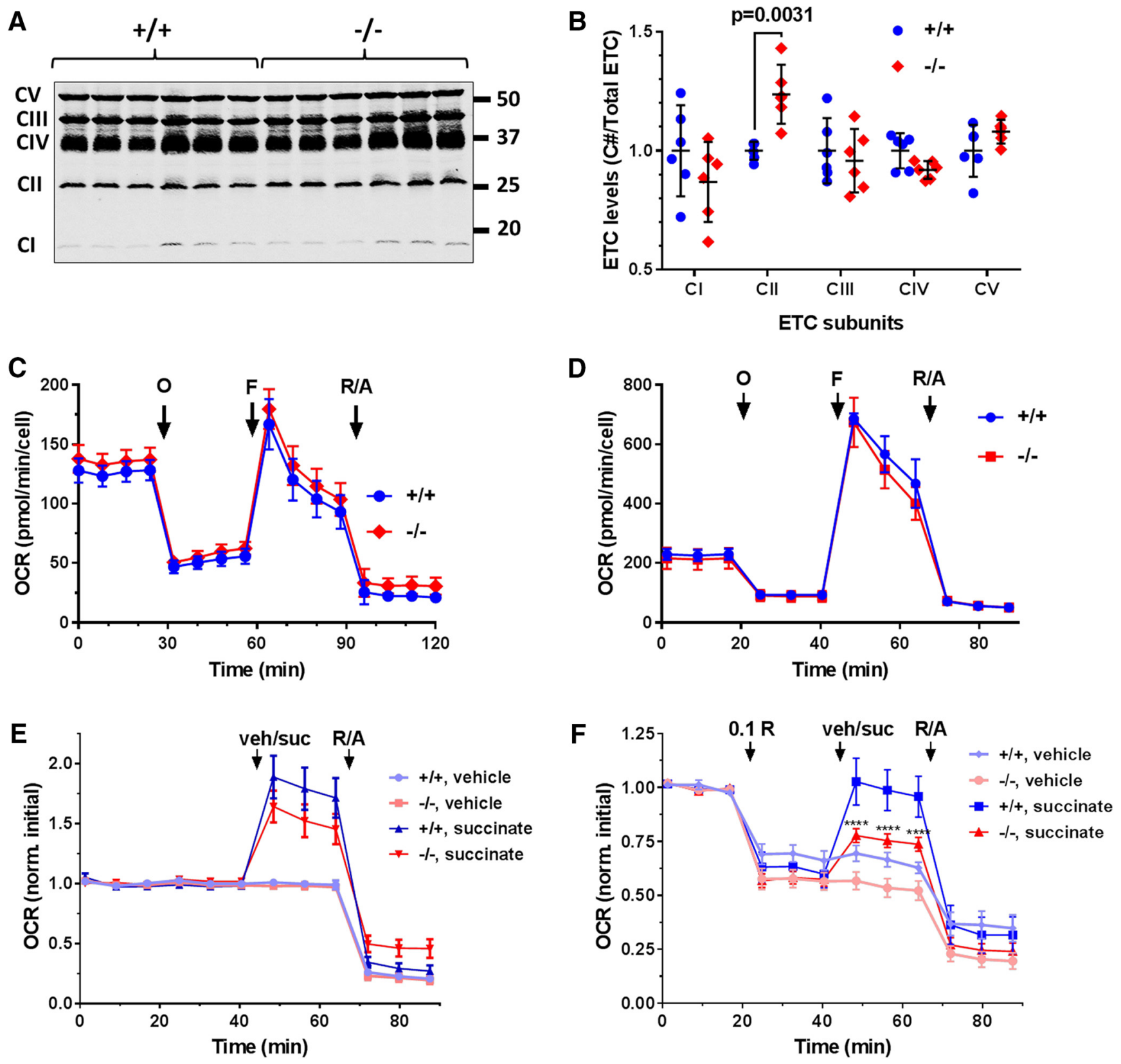

Figure 4. AKAP1 maintains respiratory complex II activity. $A$, Representative immunoblot of ETC complex subunits in mitochondrial fractions from forebrain. $\boldsymbol{B}$, Quantification of individual subunit expression relative to total ETC complex expression. Shown are mean $\pm 95 \%$ Cl. Data points represent mice (6/genotype) and were analyzed by two-way ANOVA with Sidak's multiplecomparisons test. $\boldsymbol{C}, \boldsymbol{D}$, Traces of OCR of hippocampal $(\boldsymbol{C})$ and cortical $(\boldsymbol{D})$ cultures fueled by $10 \mathrm{~mm}$ glucose in response to injection of mitochondrial inhibitors at time points indicated by black arrows [in $\mu$ m: oligomycin $(0)=2, F(F)=2$, rotenone $=10$, antimycin $A=10(R / A)$ ]. Shown are absolute mean \pm SEM of cultures from $n=3(\boldsymbol{C})$ and $n=2-4(\boldsymbol{D})$ mice/genotype. $E$, $F, 0 C R$ traces of cortical neurons cultured as in $\boldsymbol{C}$ and $\boldsymbol{D}$, but supplemented with vehicle (veh) or the complex II substrate succinate (suc; $12 \mathrm{~mm}$ ) either without $(\boldsymbol{E})$ or with $(\boldsymbol{F})$ prior inhibition of complex I with low-dose rotenone $(0.1 \mu \mathrm{m}$ ). Shown are mean \pm SEM of cultures from $n=7-8$ mice/genotype normalized to the average of the first three (basal) $0 C R$ values. Data were analyzed by repeated-measures two-way ANOVA with Tukey's post hoc test.

from hippocampus (Fig. 4C) or cortex (Fig. 4D). Complex II has a second enzymatic function as succinate dehydrogenase in the Krebs cycle. Basal OCR increased by $60-80 \%$ after supplementing cortical cultures with $12 \mathrm{~mm}$ succinate, but there was no statistically significant difference between genotypes (Fig. $4 E$ ). Succinate fuels the ETC directly through complex II, but also indirectly (via NADH produced by the Krebs cycle) through complex I. To isolate complex II-dependent respiration, complex I was inhibited with rotenone $(0.1 \mu \mathrm{M})$. With glucose as a carbon source, complex I inhibition in cortical cultures decreased OCR by $\sim 40 \%$ in both genotypes. Respiration of wild-type neurons recovered completely after succinate injection. AKAP $1^{-/-}$neurons, on the other hand, displayed a significant decrease in complex II-dependent respiration compared with wild-type neurons, recovering to only $75 \%$ of initial OCR (Fig. $4 F$ ).

Lack of AKAP1 accelerates glutamate-induced delayed calcium deregulation dependent upon the phosphorylation state of Drp1 at S637

Mitochondrial bioenergetic capacity, superoxide production and detoxification, and calcium handling are interdependent variables influencing neuronal life and death decisions. DCD is de- 
A



D



B

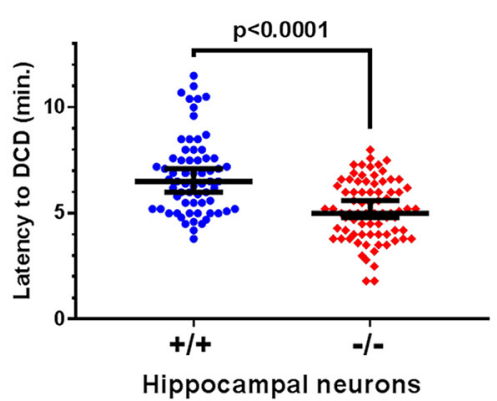

E

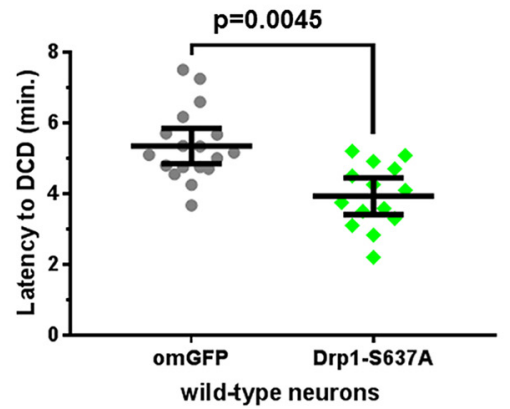

C

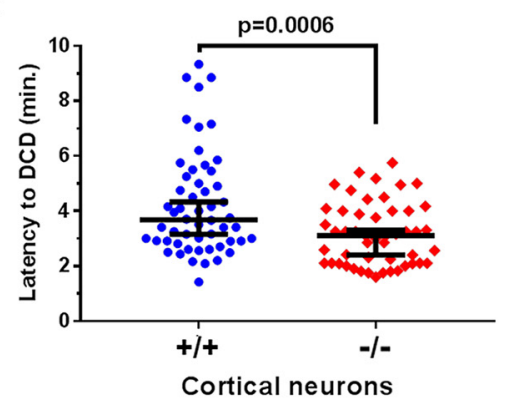

$F$

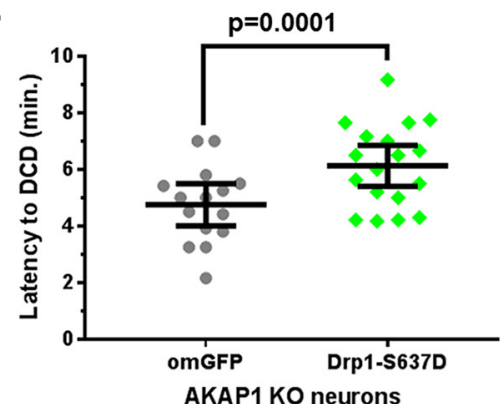

Figure 5. Deletion of AKAP1 accelerates delayed $\mathrm{Ca}^{2+}$ deregulation in response to excitotoxic glutamate exposure. $\boldsymbol{A}$, Average traces of cytosolic $\mathrm{Ca}^{2+}$ levels in primary hippocampal neurons cultured from AKAP1 $^{+/+}$and ${ }^{-1-}$ mice in response to $100 \mu \mathrm{m}$ glutamate (supplemented with $10 \mu \mathrm{m}$ glycine and 200 nm tetrodotoxin). $\boldsymbol{B}, C$, Quantification of the latency to DCD in hippocampal $(\boldsymbol{B})$ and cortical (C) cultures. Shown are medians $\pm 95 \%$ Cl with data points representing neurons from 3 to 4 mice/genotype $(n=50-77$ neurons). $\boldsymbol{D}, \boldsymbol{E}$, Latency to DCD in hippocampal neurons $\left(\boldsymbol{D}, \boldsymbol{E}, \mathrm{AKAP}^{-I-} ; \boldsymbol{F}\right.$, wild-type) expressing the indicated GFP-fusion proteins from lentiviral vectors. Data points represent neurons cultured from three mice/genotype $(\boldsymbol{D}: n=34$ for omGFP and 30 for AKAP1-GFP; $E: n=18$ for omGFP and 14 for Drp1-S637A; $F: n=15$ for omGFP and 18 for Drp1-S637D). Data are presented as mean $\pm 95 \%$ CI. All analyses by Welch's $t$ test.

fined as a large, irreversible secondary rise in intracellular $\left[\mathrm{Ca}^{2+}\right]_{\mathrm{i}}$ that follows with some latency the initial relatively small $\left[\mathrm{Ca}^{2+}\right]_{\mathrm{i}}$ increase induced by toxic glutamate exposure. Considered a "point-of-no-return", DCD coincides with mitochondrial membrane permeability transition and is followed by necrotic cell death (Nicholls et al., 2007; Abramov and Duchen, 2010; Rasola and Bernardi, 2011). AKAP1 expression is widespread and its gene is deleted constitutively in AKAP1 $1^{-/-}$mice (Newhall et al., 2006). This raises the possibility that the observed increase in stroke damage arises from AKAP1 loss in non-neuronal cells that participate in the injury response, or from developmental changes, e.g., in the vasculature. We therefore used the DCD model of excitotoxic injury combined with lentiviral protein expression to gather evidence that AKAP1 protects against ischemic injury in an acute and neuron-autonomous fashion. To this end, we monitored cytosolic $\mathrm{Ca}^{2+}$ in cultured neurons loaded with the ratiometric low-affinity $\mathrm{Ca}^{2+}$ indicator FuraFF $\left(K_{\mathrm{d}}=5.5\right.$ $\mu \mathrm{M})$ under chronic glutamate perfusion. Hippocampal neurons were challenged with $100 \mu \mathrm{M}$, while the more fragile cortical cultures received $25 \mu \mathrm{M}$ glutamate. Latency to DCD was calculated as the time between the peaks of the first derivative (or rate) of the $\left[\mathrm{Ca}^{2+}\right]_{\mathrm{i}}$ rise determined for the first and second phases of $\left[\mathrm{Ca}^{2+}\right]_{\mathrm{i}}$ elevation. AKAP1 ${ }^{-1-}$ significantly accelerated DCD, reducing the latency period from $\sim 7$ to $5 \mathrm{~min}$ in hippocampal neurons (Fig. $5 A, B$ ) and from $\sim 4$ to $3 \mathrm{~min}$ in cortical neurons (Fig. $5 C$ ). Re-expressing GFP-tagged AKAP1 via lentivirus in AKAP1 ${ }^{-/-}$ hippocampal neurons slowed the development of DCD to that seen in wild-type neurons, whereas outer-mitochondria targeted GFP (omGFP) had no effect (Fig. 5D). These results suggest that AKAP1 exerts its protective function in a neuron-autonomous manner in both hippocampus and cortex and within the timeframe of lentiviral expression (3-4d).
To interrogate the role of Drp 1 phosphorylation in neuroprotection by AKAP1, we replaced endogenous Drp1 with S637mutant GFP-Drp1 via expression of shRNA and cDNA from the same lentivirus (Cribbs and Strack, 2007; Dickey and Strack, 2011; Merrill et al., 2011). Expression of constitutively active and dephosphorylated (S637A) Drp1 in wild-type hippocampal neurons phenocopied loss of AKAP1, significantly shortening the latency to DCD compared with omGFP expression (Fig. 5E). Finally, to explore whether Drp1 phosphorylation is sufficient for protection from excitotoxicity, AKAP $1^{-/}$cultures were transduced with a phospho-mimetic Drp1 mutant (S637D) to inhibit mitochondrial fission. Drp1 constitutively phosphorylated at the PKA site rescued the increased sensitivity of AKAP $1^{-1-}$ neurons to excitotoxicity (Fig. $5 F$ ).

\section{Discussion}

Here we describe a critical role for AKAP1 in mice in regulating ischemic sensitivity. Additionally, deletion of AKAP1 promoted mitochondrial fission and Drp1 localization to mitochondria in the brain. Furthermore, deletion of AKAP1 activated mitochondrial Drp1 as evident by impaired Drp1-S637 phosphorylation at mitochondria in mice lacking AKAP1. However, loss of AKAP1 did not alter total Drp1 levels suggesting increased mitochondrial fission in mice lacking AKAP1 is due to reduced inhibitory phosphorylation and enhanced mitochondrial localization of the fission enzyme. Given that AKAP1 is rapidly degraded during hypoxia (Carlucci et al., 2008; Kim et al., 2011; Schiattarella et al., 2016) our in vivo data suggest AKAP1 expression before ischemia limits neuronal damage, presumably by stabilizing the mitochondrial network. Studies with primary neuronal cultures further indicate that AKAP1 (1) functions in an acute and neuronautonomous manner, (2) maintains respiratory complex II activity, 
(3) opposes superoxide production, and (4) controls neuronal survival by inhibiting mitochondrial fission via phosphorylation of Drp1 at S637.

An unexpected ultrastructural phenotype of the AKAP1 ${ }^{-/-}$ was an increase in the number of mitochondria-ER contacts in the hippocampal CA1 region. This phenotype was observed even in oligodendrocytes, the one cell type that did not display smaller mitochondria, and may therefore be unrelated to Drp1 modulation by PKA and AKAP1. Supportive of this notion, knockdown of AKAP1 in Drp1 $1^{-1-}$ mouse embryonic fibroblasts increased the number of contact points between mitochondria and the ER (data not shown). Importantly, recent reports suggest ER contacts play a pathological role by contributing to mitochondrial $\mathrm{Ca}^{2+}$ overload and cell death during cellular stress (Filadi et al., 2015; Park et al., 2017). The mechanism by which AKAP1 limits contacts between the two organelles and the extent to which this contributes to stroke outcomes deserve further investigation.

The observation that AKAP1 $1^{-/-}$neurons display reduced complex II activity (rotenone plus succinate), but increased expression of one of its subunits (SDHB) likewise warrants further study. It is conceivable that selective overexpression of one of four subunits compromises complex II function by sequestration of accessory proteins required for proper localization or enzymatic activity of the assembled respiratory complex. Alternatively, increased SDHB expression in mice lacking AKAP1 may be an attempt at compensation for impaired complex II activity. Such impairments could be due to abnormal posttranslational modifications of complex II subunits or altered inner membrane topology in mitochondria fragmented by genetic deletion of AKAP1.

Mitochondrial fragmentation has been reported in the transient MCAO mouse model of ischemic stroke (Barsoum et al., 2006) and several groups documented that administration of a small-molecule inhibitor of Drp1, mdivi-1, before ischemic insult ameliorates brain injury in a number of rodent stroke models (Grohm et al., 2012; Zhang et al., 2013; Li et al., 2015; Fan et al., 2017; Wu et al., 2017). However, both the specificity and efficacy of mdivi-1 as a Drp1 inhibitor have been questioned (So et al., 2012; Rosdah et al., 2016; Smith and Gallo, 2017), with a recent report demonstrating potent inhibition of complex I of the ETC instead (Bordt et al., 2017). Additionally, direct inhibition of Drp1 may have adverse effects, as postnatal genetic ablation of Drp 1 in the forebrain leads to synaptic dysfunction and cognitive impairment (Oettinghaus et al., 2016). Our findings with mice lacking an endogenous Drp1 inhibitor indicate that Drp1dependent mitochondrial fission indeed contributes to ischemic stroke damage and that targeting Drp1 regulators or Drp1 phosphorylation directly may have therapeutic potential for reducing ischemic damage.

\section{References}

Abramov AY, Duchen MR (2010) Impaired mitochondrial bioenergetics determines glutamate-induced delayed calcium deregulation in neurons. Biochim Biophys Acta 1800:297-304. CrossRef Medline

Abramov AY, Scorziello A, Duchen MR (2007) Three distinct mechanisms generate oxygen free radicals in neurons and contribute to cell death during anoxia and reoxygenation. J Neurosci 27:1129-1138. CrossRef Medline

Affaitati A, Cardone L, de Cristofaro T, Carlucci A, Ginsberg MD, Varrone S, Gottesman ME, Avvedimento EV, Feliciello A (2003) Essential role of A-kinase anchor protein 121 for cAMP signaling to mitochondria. J Biol Chem 278:4286-4294. CrossRef Medline

Barsoum MJ, Yuan H, Gerencser AA, Liot G, Kushnareva Y, Gräber S, Kovacs I, Lee WD, Waggoner J, Cui J, White AD, Bossy B, Martinou JC, Youle RJ, Lipton SA, Ellisman MH, Perkins GA, Bossy-Wetzel E (2006) Nitric oxide-induced mitochondrial fission is regulated by dynamin-related GTPases in neurons. EMBO J 25:3900-3911. CrossRef Medline

Bordt EA, Clerc P, Roelofs BA, Saladino AJ, Tretter L, Adam-Vizi V, Cherok E, Khalil A, Yadava N, Ge SX, Francis TC, Kennedy NW, Picton LK, Kumar T, Uppuluri S, Miller AM, Itoh K, Karbowski M, Sesaki H, Hill RB, Polster BM (2017) The putative Drp1 inhibitor mdivi-1 is a reversible mitochondrial complex I inhibitor that modulates reactive oxygen species. Dev Cell 40:583-594.e6. CrossRef Medline

Carlson CR, Ruppelt A, Taskén K (2003) A kinase anchoring protein (AKAP) interaction and dimerization of the $\mathrm{RI} \alpha$ and $\mathrm{RI} \beta$ regulatory subunits of protein kinase a in vivo by the yeast two hybrid system. J Mol Biol 327:609-618. CrossRef Medline

Carlucci A, Adornetto A, Scorziello A, Viggiano D, Foca M, Cuomo O, Annunziato L, Gottesman M, Feliciello A (2008) Proteolysis of AKAP121 regulates mitochondrial activity during cellular hypoxia and brain ischaemia. EMBO J 27:1073-1084. CrossRef Medline

Castilho RF, Ward MW, Nicholls DG (1999) Oxidative stress, mitochondrial function, and acute glutamate excitotoxicity in cultured cerebellar granule cells. J Neurochem 72:1394-1401. Medline

Cereghetti GM, Stangherlin A, Martins de Brito O, Chang CR, Blackstone C, Bernardi P, Scorrano L (2008) Dephosphorylation by calcineurin regulates translocation of Drp1 to mitochondria. Proc Natl Acad Sci U S A 105:15803-15808. CrossRef Medline

Chang CR, Blackstone C (2007) Cyclic AMP-dependent protein kinase phosphorylation of Drp1 regulates its GTPase activity and mitochondrial morphology. J Biol Chem 282:21583-21587. CrossRef Medline

Chang CR, Blackstone C (2010) Dynamic regulation of mitochondrial fission through modification of the dynamin-related protein Drp1. Ann N Y Acad Sci 1201:34-39. CrossRef Medline

Cribbs JT, Strack S (2007) Reversible phosphorylation of Drpl by cyclic AMP-dependent protein kinase and calcineurin regulates mitochondrial fission and cell death. EMBO Rep 8:939-944. CrossRef Medline

Dagda RK, Gusdon AM, Pien I, Strack S, Green S, Li C, Van Houten B, Cherra SJ 3rd, Chu CT (2011) Mitochondrially localized PKA reverses mitochondrial pathology and dysfunction in a cellular model of Parkinson's disease. Cell Death Differ 18:1914-1923. CrossRef Medline

Dhanesha N, Ahmad A, Prakash P, Doddapattar P, Lentz SR, Chauhan AK (2015) Genetic ablation of extra domain A of fibronectin in hypercholesterolemic mice improves stroke outcome by reducing thromboinflammation. Circulation 132:2237-2247. CrossRef Medline

Dickey AS, Strack S (2011) PKA/AKAP1 and PP2A/Bbeta2 regulate neuronal morphogenesis via Drp1 phosphorylation and mitochondrial bioenergetics. J Neurosci 31:15716-15726. CrossRef Medline

Fan LF, He PY, Peng YC, Du QH, Ma YJ, Jin JX, Xu HZ, Li JR, Wang ZJ, Cao SL, Li T, Yan F, Gu C, Wang L, Chen G (2017) Mdivi-1 ameliorates early brain injury after subarachnoid hemorrhage via the suppression of inflammation-related blood-brain barrier disruption and endoplasmic reticulum stress-based apoptosis. Free Radic Biol Med 112:336-349. CrossRef Medline

Filadi R, Greotti E, Turacchio G, Luini A, Pozzan T, Pizzo P (2015) Mitofusin 2 ablation increases endoplasmic reticulum-mitochondria coupling. Proc Natl Acad Sci U S A 112:E2174-2181. CrossRef Medline

Flippo KH, Strack S (2017a) An emerging role for mitochondrial dynamics in schizophrenia. Schizophr Res 187:26-32. CrossRef Medline

Flippo KH, Strack S (2017b) Mitochondrial dynamics in neuronal injury, development and plasticity. J Cell Sci 130:671-681. CrossRef Medline

Friedman JR, Lackner LL, West M, DiBenedetto JR, Nunnari J, Voeltz GK (2011) ER tubules mark sites of mitochondrial division. Science 334: 358-362. CrossRef Medline

Giorgi-Coll S, Amaral AI, Hutchinson PJA, Kotter MR, Carpenter KLH (2017) Succinate supplementation improves metabolic performance of mixed glial cell cultures with mitochondrial dysfunction. Sci Rep 7:1003. CrossRef Medline

Grohm J, Kim SW, Mamrak U, Tobaben S, Cassidy-Stone A, Nunnari J, Plesnila N, Culmsee C (2012) Inhibition of Drpl provides neuroprotection in vitro and in vivo. Cell Death Differ 19:1446-1458. CrossRef Medline

Herberg FW, Maleszka A, Eide T, Vossebein L, Tasken K (2000) Analysis of A-kinase anchoring protein (AKAP) interaction with protein kinase $\mathrm{A}$ (PKA) regulatory subunits: PKA isoform specificity in AKAP binding. J Mol Biol 298:329-339. CrossRef Medline

Hori M, Nakamachi T, Rakwal R, Shibato J, Nakamura K, Wada Y, Shioda S, 
Tsuchikawa D, Yoshikawa A, Tamaki K, Shioda S (2012) Unraveling the ischemic brain transcriptome in a permanent middle cerebral artery occlusion mouse model by DNA microarray analysis. Dis Model Mech 5:270-283. CrossRef Medline

Jahani-Asl A, Huang E, Irrcher I, Rashidian J, Ishihara N, Lagace DC, Slack RS, Park DS (2015) CDK5 phosphorylates DRP1 and drives mitochondrial defects in NMDA-induced neuronal death. Hum Mol Genet 24: 4573-4583. CrossRef Medline

Jun YW, Park H, Lee YK, Kaang BK, Lee JA, Jang DJ (2016) D-AKAP1a is a signal-anchored protein in the mitochondrial outer membrane. FEBS Lett 590:954-961. CrossRef Medline

Kim H, Scimia MC, Wilkinson D, Trelles RD, Wood MR, Bowtell D, Dillin A, Mercola M, Ronai ZA (2011) Fine-tuning of Drp1/Fis1 availability by AKAP121/Siah2 regulates mitochondrial adaptation to hypoxia. Mol Cell 44:532-544. CrossRef Medline

Koopman WJ, Distelmaier F, Smeitink JA, Willems PH (2013) OXPHOS mutations and neurodegeneration. EMBO J 32:9-29. CrossRef Medline

Li Y, Wang P, Wei J, Fan R, Zuo Y, Shi M, Wu H, Zhou M, Lin J, Wu M, Fang $X$, Huang Z (2015) Inhibition of Drp1 by mdivi-1 attenuates cerebral ischemic injury via inhibition of the mitochondria-dependent apoptotic pathway after cardiac arrest. Neuroscience 311:67-74. CrossRef Medline

Ma Y, Taylor SS (2008) A molecular switch for targeting between endoplasmic reticulum (ER) and mitochondria: conversion of a mitochondriatargeting element into an ER-targeting signal in DAKAP1. J Biol Chem 283:11743-11751. CrossRef Medline

Marchi S, Patergnani S, Pinton P (2014) The endoplasmic reticulummitochondria connection: one touch, multiple functions. Biochim Biophys Acta 1837:461-469. CrossRef Medline

Merrill RA, Strack S (2014) Mitochondria: a kinase anchoring protein 1, a signaling platform for mitochondrial form and function. Int J Biochem Cell Biol 48:92-96. CrossRef Medline

Merrill RA, Slupe AM, Strack S (2013) N-terminal phosphorylation of protein phosphatase $2 \mathrm{~A} / \mathrm{Bbeta} 2$ regulates translocation to mitochondria, dynamin-related protein 1 dephosphorylation, and neuronal survival. FEBS J 280:662-673. CrossRef Medline

Merrill RA, Dagda RK, Dickey AS, Cribbs JT, Green SH, Usachev YM, Strack S (2011) Mechanism of neuroprotective mitochondrial remodeling by PKA/AKAP1. PLoS Biol 9:e1000612. CrossRef Medline

Newhall KJ, Criniti AR, Cheah CS, Smith KC, Kafer KE, Burkart AD, McKnight GS (2006) Dynamic anchoring of PKA is essential during oocyte maturation. Curr Biol 16:321-327. CrossRef Medline

Nicholls DG (2004) Mitochondrial dysfunction and glutamate excitotoxicity studied in primary neuronal cultures. Curr Mol Med 4:149-177. CrossRef Medline

Nicholls DG, Johnson-Cadwell L, Vesce S, Jekabsons M, Yadava N (2007) Bioenergetics of mitochondria in cultured neurons and their role in glutamate excitotoxicity. J Neurosci Res 85:3206-3212. CrossRef Medline

Oettinghaus B, Schulz JM, Restelli LM, Licci M, Savoia C, Schmitt K, Grimm A, Morè L, Hench J, Tolnay M, Eckert A, D’Adamo P, Franken P, Ishihara N, Mihara K, Bischofberger J, Scorrano L, Frank S (2016) Synaptic dysfunction, memory deficits and hippocampal atrophy due to ablation of mitochondrial fission in adult forebrain neurons. Cell Death Differ 23: 18-28. CrossRef Medline

Otera H, Ishihara N, Mihara K (2013) New insights into the function and regulation of mitochondrial fission. Biochim Biophys Acta 1833:12561268. CrossRef Medline

Park SJ, Lee SB, Suh Y, Kim SJ, Lee N, Hong JH, Park C, Woo Y, Ishizuka K, Kim JH, Berggren PO, Sawa A, Park SK (2017) DISC1 modulates neuronal stress responses by gate-keeping ER-mitochondria $\mathrm{Ca}^{2+}$ transfer through the MAM. Cell Rep 21:2748-2759. CrossRef Medline

Perkins GA, Renken CW, Frey TG, Ellisman MH (2001) Membrane architecture of mitochondria in neurons of the central nervous system. J Neurosci Res 66:857-865. CrossRef Medline

Prudent J, McBride HM (2016) Mitochondrial dynamics: ER actin tightens the Drp1 noose. Curr Biol 26:R207-R209. CrossRef Medline

Pryde KR, Smith HL, Chau KY, Schapira AH (2016) PINK1 disables the anti-fission machinery to segregate damaged mitochondria for mitophagy. J Cell Biol 213:163-171. CrossRef Medline

Qi X, Disatnik MH, Shen N, Sobel RA, Mochly-Rosen D (2011) Aberrant mitochondrial fission in neurons induced by protein kinase $\mathrm{C} \delta$ under oxidative stress conditions in vivo. Mol Biol Cell 22:256-265. CrossRef Medline

Ramos-Cabrer P, Campos F, Sobrino T, Castillo J (2011) Targeting the ischemic penumbra. Stroke 42:S7-S11. CrossRef Medline

Rasola A, Bernardi P (2011) Mitochondrial permeability transition in $\mathrm{Ca}^{2+}$-dependent apoptosis and necrosis. Cell Calcium 50:222-233. CrossRef Medline

Rosdah AA, K Holien J, Delbridge LM, Dusting GJ, Lim SY (2016) Mitochondrial fission: a drug target for cytoprotection or cytodestruction? Pharmacol Res Perspect 4:e00235. CrossRef Medline

Schiattarella GG, Cattaneo F, Pironti G, Magliulo F, Carotenuto G, Pirozzi M, Polishchuk R, Borzacchiello D, Paolillo R, Oliveti M, Boccella N, Avvedimento M, Sepe M, Lombardi A, Busiello RA, Trimarco B, Esposito G, Feliciello A, Perrino C (2016) Akap1 deficiency promotes mitochondrial aberrations and exacerbates cardiac injury following permanent coronary ligation via enhanced mitophagy and apoptosis. PLoS One 11: e0154076. CrossRef Medline

Schnizler K, Shutov, LP, Van Kanegan MJ, Merrill MA, Nichols B, McKnight GS, Strack S, Hell JW, Usachev, YM (2008) Protein kinase A anchoring via AKAP150 is essential for TRPV1 modulation by forskolin and prostaglandin E2 in mouse sensory neurons. J Neurosci 28:4904-4917. CrossRef Medline

Slupe AM, Merrill RA, Flippo KH, Lobas MA, Houtman JC, Strack S (2013) A calcineurin docking motif (LXVP) in dynamin-related protein 1 contributes to mitochondrial fragmentation and ischemic neuronal injury. J Biol Chem 288:12353-12365. CrossRef Medline

Smith G, Gallo G (2017) To mdivi-1 or not to mdivi-1: is that the question? Dev Neurobiol 77:1260-1268. CrossRef Medline

So EC, Hsing CH, Liang CH, Wu SN (2012) The actions of mdivi-1, an inhibitor of mitochondrial fission, on rapidly activating delayed-rectifier $\mathrm{K}(+)$ current and membrane potential in HL-1 murine atrial cardiomyocytes. Eur J Pharmacol 683:1-9. CrossRef Medline

Sugawara T, Fujimura M, Morita-Fujimura Y, Kawase M, Chan PH (1999) Mitochondrial release of cytochrome c corresponds to the selective vulnerability of hippocampal CA1 neurons in rats after transient global cerebral ischemia. J Neurosci 19:RC39. CrossRef Medline

Taguchi N, Ishihara N, Jofuku A, Oka T, Mihara K (2007) Mitotic phosphorylation of dynamin-related GTPase Drp1 participates in mitochondrial fission. J Biol Chem 282:11521-11529. CrossRef Medline

Uo T, Dworzak J, Kinoshita C, Inman DM, Kinoshita Y, Horner PJ, Morrison RS (2009) Drp1 levels constitutively regulate mitochondrial dynamics and cell survival in cortical neurons. Exp Neurol 218:274-285. CrossRef Medline

Vance JE (2014) MAM (mitochondria-associated membranes) in mammalian cells: lipids and beyond. Biochim Biophys Acta 1841:595-609. CrossRef Medline

Wang C, Liu M, Pan Y, Bai B, Chen J (2017) Global gene expression profile of cerebral ischemia-reperfusion injury in rat MCAO model. Oncotarget 8:74607-74622. CrossRef Medline

Wang X, Leverin AL, Han W, Zhu C, Johansson BR, Jacotot E, Ten VS, Sims NR, Hagberg H (2011) Isolation of brain mitochondria from neonatal mice. J Neurochem 119:1253-1261. CrossRef Medline

Wu P, Li Y, Zhu S, Wang C, Dai J, Zhang G, Zheng B, Xu S, Wang L, Zhang T, Zhou P, Zhang JH, Shi H (2017) Mdivi-1 alleviates early brain injury after experimental subarachnoid hemorrhage in rats, possibly via inhibition of Drp1-activated mitochondrial fission and oxidative stress. Neurochem Res 42:1449-1458. CrossRef Medline

Zhang N, Wang S, Li Y, Che L, Zhao Q (2013) A selective inhibitor of Drp1, mdivi-1, acts against cerebral ischemia/reperfusion injury via an antiapoptotic pathway in rats. Neurosci Lett 535:104-109. CrossRef Medline

Zhao YX, Cui M, Chen SF, Dong Q, Liu XY (2014) Amelioration of ischemic mitochondrial injury and bax-dependent outer membrane permeabilization by mdivi-1. CNS Neurosci Ther 20:528-538. CrossRef Medline 